\title{
O Gif animado de reação e o processo de descontextualização
}

\author{
Paulo Korpys \\ CECS - Centro de Estudos de Comunicação e Sociedade, Portugal \\ Pedro Mota Teixeira \\ ID+ - Instituto de Investigação em Design, Media e Cultura, Portugal \\ Daniel Brandão \\ CECS - Centro de Estudos de Comunicação e Sociedade, Portugal \\ António Ferreira \\ CECS - Centro de Estudos de Comunicação e Sociedade, Portugal
}

\begin{abstract}
Animated Gif continues to be widely used by users in digital media. It's an image format with over thirty years old, that has changed little since its inception. Its main features remain the same, yet they seem to be an ideal package and conducive to proliferation through the digital world. This paper intends to contextualize the animated Gif as a media and provide a perspective about why it continues to be such a relevant format for cyberculture today. Therefore, the reaction Gif is the chosen object to be covered in this paper. The consequent decontextualization levels of Gifs, from multiple situations, are also explored. From the personal interpretation of each user, infinite new meanings and new Gifs can emerge depending on a specific context of communication, shaped by sociocultural factors.
\end{abstract}

Keywords: Gif, Reaction Gif, Decontextualization, Cyberculture, New Media, Communication

\section{Contextualização}

Clive Thompson, abordando o Gif animado no seu artigo online para a Wired, termina o seu texto com a seguinte afirmação: "cento e trinta anos depois, ainda vivemos a era de Muybridge" (Thompson 2013). O mistério e a curiosidade de tal afirmação levaram-nos à construção deste texto no sentido de desenvolver um contributo acerca da importância do Gif animado, enquanto média, nos dias que correm. Eadweard Muybridge, o magic lantern showman, viajava por ambos os lados do Atlântico com o intuito de apresentar ao público os seus resultados, recorrendo à sua própria invenção, o zoopraxiscópio (Fresko 2013, 48). Conhecido pelas suas aulas, projeções e animações, Muybridge proporcionava uma experiência emocionante a alunos, professores, e também a um público generalizado daquela época, causando uma sensação diferente em todos os observadores que contemplavam animações oriundas do seu estudo sobre locomoção animal (Fresko 2013, 48). A associação sugerida por Thompson, entre a era de Muybridge e a cibercultura atual, aparenta estar relacionada com as características visuais que tanto as projeções de Muybridge, como os Gifs animados, possuem em comum. No entanto, consideramos que exista outro motivo. Assistimos atualmente a uma era digital "onde se não se espalhar, está morto"
(Jenkins, Ford, and Green 2013, 188), tal como Jenkins, Ford e Green nos sugerem. No entanto, tendo em consideração diferentes proporções e épocas, acreditamos que, caso os resultados do estudo de Muybridge não se espalhassem e chegassem às pessoas, é como se também nunca tivessem existido. Ainda a respeito deste paralelo entre o passado e o presente, destacamos as seguintes palavras de Hesselberth e Poulaki, no seu texto introdutório ao livro Compact Cinematics:

\begin{abstract}
Historicamente, desde brinquedos précinematográficos (...) até curtas-metragens, filmes de vanguarda, videoarte, filmes QuickTime, machinima e GIFs animados, o amplo uso e consumo de formas cinematográficas compactas, práticas, e artefactos, sugerem que compactação não é uma curiosidade inusitada às margens do cinema, mas existiu mesmo antes da padronização do cinema na forma teatral, e nos últimos anos se multiplicou e proliferou, ocupando uma parte cada vez mais importante do nosso ambiente multimédia do dia-adia (Hesselberth and Poulaki 2018, 2).
\end{abstract}

Atualmente este processo de proliferação acontece com uma grande velocidade e facilidade devido às características das ferramentas online (Jenkins, Ford, and Green 2013, 12), que potenciam de forma exponencial todas as etapas. Outrora, pressupomos que exigisse outro tipo de soluções. Da atenção de Hesselberth e Poulaki ao comportamento da imagem nesta "paisagem saturada pelos média" (Hesselberth and Poulaki 2018, 8), interpretamos que Michel Maffesoli e Moisés Martins possuem uma visão idêntica pois "deixamos, entretanto, de olhar para as estrelas e passamos a olhar para os ecrãs, como assinala Virilio. Ou seja, da história de sentido em que se inscreviam as estrelas, o Ocidente abriu caminho para os ecrãs. E nesta travessia atribuiu-se uma "pele tecnológica» (Kerckhove), uma pele para a afeção, ou seja, para o ser-com-outros" (Maffesoli and Martins 2011, 44). Calculamos que o conceito de pele tecnológica, que Maffesoli e Martins referem, é uma forma assertiva de resumir os fenómenos sociais e culturais que assistimos diariamente. Uma pele tecnológica que tira partido dos facilitados processos, com os quais nos deparamos diariamente, dos média digitais. Segundo a definição de Lev Manovich, os Gifs animados encaixam-se naquilo que o próprio denomina de "objeto dos novos média" (Manovich 2002) e também argumenta que esta é a sociedade do ecrã (Manovich 2002), onde partilhar 
é talvez a palavra-chave que descreva de uma forma mais generalizada os fenómenos do mundo digital (Shifman 2014, 19). O consumidor de ecrã é hoje um espetador solitário, individualista (Väliaho 2018, 128; Shifman 2014, 33) e assim como Väliaho descreve, um pequeno ecrã tem um poder mental de tal forma acentuado, que possibilita a formação de um manto psíquico e envolve o utilizador, isolando-o do mundo exterior e tornando-o invisível (Väliaho 2018, 128). Väliaho também estabelece uma comparação entre o ecrã coletivo do passado e o ecrã individualista do presente (Väliaho 2018, 128-29). Individual, invisível ao mundo exterior, atrás dos ecrãs. Possivelmente visível, coletivo, neste mundo virtual pautado "por sequências de zeros e uns" (Sousa, Zagalo, and Martins 2012, 172), para lá dos ecrãs. Segundo José Neves e Zara PintoCoelho, e "de acordo com Sennet (2004), estando cada vez mais isolados dos velhos laços da comunidade, (...) erramos em direcção ao vazio ou a qualquer coisa" (Neves and Pinto-Coelho 2010, 5). Estes conceitos remetem-nos para a construção de uma identidade digital, uma online persona, que acreditamos diferir da identidade com que nos apresentamos no mundo real. No mesmo sentido, pensamos que possa existir espaço para abordar a questão da identidade de uma outra perspetiva, expandindo-a para a forma como a cibercultura afeta não só a identidade pessoal, na nossa ótica, mas também a identidade coletiva, moldando a cultura, a sociedade, a tradição. "O Homo sapiens fundiu-se com o Homo numericus, ou seja, fundiu-se com lógicas sócio-técnicas" (Maffesoli and Martins 2011, 48). Max Nordau na sua obra Degeneração, recuando mais de um século, notou a dificuldade que as sociedades citadinas se depararam para aguentar a corrente da modernidade, o crescente e frenético ritmo das cidades que tomou todos de rompante, fatigando-os, degenerando-os (Nordau 1898). Nos dias que correm, de uma ótica sobre as atuais consequências tecnológicas, Pinheiro e Pinto-Coelho defendem que "neste esvaziamento, começamos a tentar coisas novas, uma espécie de vagabundagem centrada no emocional que tanto nos pode libertar como pode aumentar a insatisfação e levar-nos para novas dependências. É aqui que surge o fenómeno das nossas ligações com os ecrãs digitais como uma saída (em grande parte ilusória) para esta crise do mundo moderno" (Neves and Pinto-Coelho 2010, 5). Acreditamos que a vertente tecnológica ao mesmo tempo nos dá e ao mesmo tempo nos tira, numa espiral aparentemente sem fim à vista. Tornamo-nos cavaleiros pós-modernistas como Maffesoli e Martins metaforicamente definem (Maffesoli and Martins 2011, 50), navegando "na Internet à procura de um Graal, o qual, todavia, à semelhança de todo o Graal, não tem contornos, nem conteúdo preciso. De importante mesmo, apenas o caminho, a vagabundagem, o próprio acto de «navegar»" (Maffesoli and Martins 2011, 50). Da abordagem metafórica de Maffesoli e Martins entendemos a imprevisibilidade do que estará para vir, de que forma continuará a afetar as sociedades, e quais as consequências, sejam elas positivas ou negativas, que poderemos vir a identificar. Freitas e Pereira afirmam que o universo digital não pode ser construído à parte da sociedade, num "vácuo cultural" (Freitas and Pereira 2017,196$)$ pois "a nossa própria compreensão depende dos nossos hábitos, das situações em que nos encontramos: a investigação não pode limitarse aos objectos a que chamamos imagens. Deve ser alargada às sociedades que as utilizam" (Gardies 2006, 181), de acordo com René Gardies.

Segundo as palavras de Jason Feifer, o Gif "é uma imagem em loop usada em toda a Internet - a coisa que não é bem um vídeo, que não tem botão de reprodução nem som, que se repete até desviar o olhar. É lingua franca nos média sociais" (Feifer 2016, 26). Passamos a introduzir algumas breves características do Gif animado comuns às suas diversas utilizações. É um formato de imagem para a Web e não um formato de vídeo. Possui sim, à semelhança de formatos de vídeo, a capacidade de apresentar imagem em movimento apesar de também poder ser utilizado para apresentar imagem estática. Derivado das suas características técnicas, uma imagem em formato Gif normalmente é um ficheiro leve e rapidamente carregado na internet. Não oferece possibilidade, nativamente, de contemplar som. Normalmente é utilizado para apresentar sequências de poucos segundos, sempre numa reprodução cíclica e infinita, ou seja, numa reprodução mais comummente apelidada de loop. O loop automático do Gif é possivelmente a característica mais imediata que podemos identificar em comum com as sequências de Muybridge e os brinquedos óticos do século XIX que, ao contrário do Gif animado, eram acionados manualmente. Desde a sua criação, em 1987, pela equipa de Steve Wilhite (Eppink 2014, 301), que o objetivo passava pela criação de um formato de imagem com o intuito de ser facilmente partilhado (McCarthy 2018, 114). Tal como em 1987, nos dias que correm esta aparenta ser uma das características que torna o Gif tão versátil e maleável (Miltner and Highfield 2017, 2). O loop permite ao Gif animado realçar determinado conteúdo (Miltner and Highfield 2017,6 ), que de outra forma poderia passar despercebido a um olhar distraído. A ausência de som é uma característica que podemos identificar nos Gifs. Ao contrário do vídeo, onde normalmente existe uma faixa de áudio, os Gifs podem ser consumidos em espaços públicos sem incomodar as pessoas em redor (Bakhshi et al. 2016, 579) e Michael Newman defende que os Gifs são "como os primeiros exemplos de cinema, e capturam um pouco da mesma magia da vida em movimento que impressionaram os primeiros públicos de cinema" (Newman 2016). Consumidos sem incomodar, esta ideia aparenta entrar em concordância com o manto psíquico que Väliaho defende, contribuindo para a sua construção. No entanto, apesar de silenciosos, Bakhshi et al. descrevem os Gifs "como divertidos foguetes de garrafa" (Bakhshi et al. 2016, 581). Pressupomos, desta definição de Bakhshi et al., que seja pela forma como estas pequenas animações conseguem "roubar" o nosso olhar, a nossa atenção para comunicações rápidas, fluídas, interativas. 
Um meio de comunicação tem uma influência importante na disseminação do conhecimento ao longo do espaço e ao longo do tempo e torna-se necessário estudar as suas características para avaliar a sua influência no seu ambiente cultural. De acordo com suas características, pode ser mais adequado à disseminação do conhecimento ao longo do tempo do que do espaço, particularmente se o meio é pesado e durável, mas desadequado para transporte, ou para a disseminação de conhecimento ao longo do espaço do que ao longo do tempo, particularmente se o meio é leve e facilmente transportável (Innis 2008, 33).

Constatamos outra característica do Gif, a sua efemeridade. Ou seja, pode-se acrescentar que o Gif é de certa forma, descartável, pois aparenta possuir um tempo de vida útil muito curto em cada utilização. Desta forma, entende-se as características do Gif animado como um veículo de disseminação ao longo do espaço do que ao longo do tempo, de acordo com o conceito apresentado por Harold Innis (Innis 2008, 33). "Mais uma coisa que torna os GIFs ótimos: eles são facilmente partilhados. Eles fazem parte de um crescente conjunto cultural de arquivos de imagens para uso em diversas finalidades: na conversa, nas expressões de fandom ou na crítica" (Newman 2016). Para além destas finalidades sugeridas por Newman, os Gifs também podem ser usados em mais plataformas como blogs, fóruns, redes sociais, etc.

Ao longo deste artigo pretendemos abordar a importância do Gif animado na cibercultura e compreender como é que uma tecnologia com mais de trinta anos, acreditando que das suas limitações fez as suas forças, continua a ser tão relevante na cultura digital atraindo cada vez mais utilizadores. Com este objetivo, através de uma investigação bibliográfica sobre o Gif animado, tentaremos interpretar o que se discute acerca do Gif no sentido de construir um contributo acerca da sua preponderância. Para isso, centramos este artigo em dois pontos: o Gif de reação e o consequente processo de descontextualização.

\section{Gif de reação}

Um Gif de reação (Figura 1) é empregue num contexto onde a sua função é efetivamente reagir a um determinado assunto, de forma emocional. Este pode ser utilizado em forma de reação em posts, em chats, em comentários de redes sociais, em e-mails, etc. Entendemos que esta versatilidade de utilização como forma de induzir emoção é uma vantagem para a cibercultura. O próprio Gif pode conter uma legenda embutida, acompanhando a comunicação dos restantes elementos que por lá figuram. "Gifs animados são talvez um meio visual que permite exprimir gestos" (Bakhshi et al. 2016, 584) e "essas demonstrações do Gif devem ser tomadas como ações do próprio contribuidor" (Tolins and Samermit 2016, 76). Estes afetos "experimentados pelos seres humanos são, em última análise, moldados pela situação social e histórica de um indivíduo" (Hillis, Paasonen, and Petit 2015, 131).
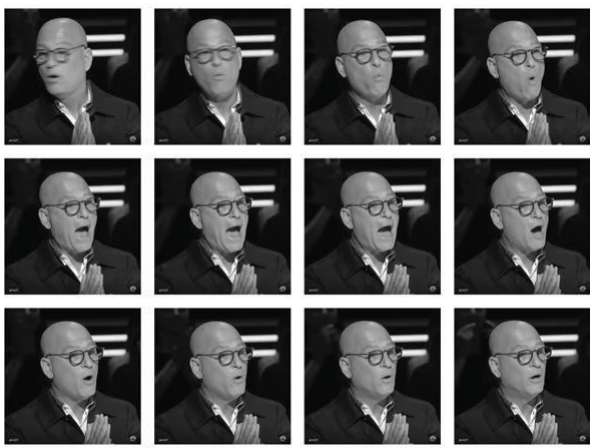

Figura 1: Gif, dividido pelos seus fotogramas, de Howdie Mendel expressando surpresa. Fonte: Giphy (https://gph. is/2LyQyn4)

McCarthy refere-nos metaforicamente que os Gifs de reação são utilizados "da mesma forma que os jogadores descartam cartas num jogo de trunfos, cada vez apontando para o sítio certo" (McCarthy 2018, 113). A conceção deste tipo de Gifs tem grande incidência em produtos do cinema e da televisão (Tolins and Samermit 2016, 76), onde constatamos que o utilizador se apodera do trabalho de expressão de outras pessoas, animais, objetos, e emprega-o como se fosse a sua própria ação. Os "Gifs animados estão a desempenhar um papel cada vez mais importante nos média sociais, entregando notícias de última hora, contando histórias por meio de fotojornalismo e possibilitando novas maneiras de expressar emoções" (Bakhshi et al. 2016, 575). Em 2012, Gif foi considerada a palavra do ano para a Oxford Dictionaries nos Estados Unidos da América, adquirindo a forma de verbo: to gif (Martin 2012). Julgamos que este facto permitiu ramificações como "escovando o seu ombro instantaneamente de uma forma giffable" (Feifer 2016, 34). De uma forma giffable, ou seja, de uma forma que julgamos propícia e merecedora de conversão em Gif animado, para ser utilizado de forma ilimitada em diversos contextos de comunicação. Esta forma giffable pode também estar relacionada com o caráter humorístico, irónico, sarcástico, que aparenta estar inerente aos utilizadores que se apropriam do Gif, para reagir de forma efusiva a eventos do quotidiano. Assim sendo, os Gifs passaram a ser utilizados "em resposta a", ou seja, em reação a determinado contexto e por vezes utilizados "em vez de texto" (Eppink 2014, 303). Segundo vários autores, canais de comunicação por texto e mediados por computador, como chats e e-mails, podem sofrer um défice de comunicação não-verbal (Burgoon, Guerrero, and Floyd 2016, 4; Tolins and Samermit 2016, 75; Schmidt 2013, 367). Nesta ótica, os Gifs de reação podem constituir uma solução para compensar este défice de comunicação não-verbal pois entendemos a não-verbalidade do Gif de reação como um dos seus pontos mais fortes. É uma possível linguagem visual onde "estamos na intencionalidade, quer seja o leitor que a manifeste ou que se convide esse leitor a reconhecê-la" (Gardies 2006, 186) e "se as línguas 
decorrem da linguagem, nem todas as linguagens são línguas" (Gardies 2006, 184). Os Gifs podem ser ricos visualmente e emocionalmente, facilitando a interpretação de emoções quando, por vezes, com recurso a palavras se torna mais complicada e demorada a expressão do pretendido. No estudo efetuado por Bakhshi et al., normalmente existem "duas formas de Gifs de reação: reais e hipotéticos" (Bakhshi et al. 2016, 583). Os reais são utilizados em resposta direta a um assunto factual, enquanto os hipotéticos são aplicados numa reação a um possível assunto, ou seja, na hipótese de. Os reais, por exemplo em chats, são aplicados diretamente para reagir a um acontecimento apresentado pelo outro utilizador. Os hipotéticos implicam uma situação fundada na hipótese, "como eu me sinto quando" ou "a minha reação quando" me deparo com determinado fenómeno. Quando estes Gifs são interpretados por quem os recebe, a "emoção percebida é a emoção que eles pensam que o Gif expressa ao contrário da emoção que eles sentem (emoção induzida)" (Chen, Rudovic, and Picard 2017, 511). Maffesoli e Martins também chegam a uma resposta similar, "dado que a partilha das imagens faz com que sejamos pensados pelo outro, faz com que não existamos senão através e debaixo do olhar do outro" (Maffesoli and Martins 2011, 47).

"Gifs estão entre os formatos ideais para ilustração na crítica do cinema, permitindo uma nova forma de citação da imagem em movimento" (Newman 2016). Acreditamos que, não só na crítica do cinema, o Gif pode ser uma poderosa ferramenta de citação. Aquando da utilização dos Gifs de reação, entendemos que passamos constantemente a citar conteúdos visuais apropriando-se dos seus fotogramas para induzir emoção. Daquele conteúdo cinematográfico ou televiso, por exemplo, apoderamo-nos de uma parte da sua sequência e fazemos, por momentos, com que seja nossa, aplicando-lhe novas camadas de significado, descontextualizando o produto original. Citamos visualmente, induzimos emoção e criamos novos significados a cada utilização dependendo de um contexto envolvente. Neste momento entramos na fase interpretativa do Gif. A polissemia inerente ao caráter do Gif é provavelmente uma das características com mais potencial de exploração, uma vez que a criação de sentido pode variar do contexto sociocultural. Esta capacidade de adaptação a diversos contextos pode demonstrar toda a sua versatilidade. Apesar da sua versatilidade de utilização como meio de comunicação, as pessoas que, por norma, figuram nos Gifs de reação são "sujeitos que não passam de imagens sem aura" (Martins 2016, 327), numa "total artificialização dos retratos, que passam ao não-lugar da impessoalidade, como se fossem objectos produzidos para consumo" (Martins 2016, 327). Aqui centramos uma analogia entre quem figura nos Gifs animados e as obras expostas em "Novas Faces", analisadas por Moisés Martins e criadas por Pintomeira. Das palavras de Martins aplicadas neste contexto, deduzimos que os Gifs de reação funcionam como uma máscara para o utilizador. Uma máscara que pode assumir qualquer forma, composição, cor, gesto, textura, velocidade, luz, etc. E como qualquer máscara, esta reside na impessoalidade de uma "imagem sem aura" que pretende mascarar o utilizador de emoções com recurso às ações de outrem. Portanto, tanto utilizadores como os sujeitos que figuram nos Gifs tendem a encontrarem-se na impessoalidade.

Gif animado pressupõe animação, imagem em movimento. Imagem a imagem em sequência, a ilusão de movimento, construindo uma determinada narrativa dentro de um determinado enunciado, "um Gif animado é uma coisa mágica. Contém o poder de transmitir emoção, empatia e contextualiza de uma maneira subtil que o texto ou os emoticons simplesmente não conseguem" (Rich and Hu n.d.). Recorrendo a um conceito também associado à área da animação digital, a empatia, calculamos que seja pertinente referi-la, transportando-a da animação para o mundo reacional dos Gifs animados. Segundo Ed Hooks, "'empatia' significa literalmente 'sentir-se em'. Quando temos empatia com alguém, sentimos o que ele está sentindo; identificámo-nos com os seus valores" (Hooks 2017). Calculamos que resida aqui o propósito de induzir emoção através do Gif animado: criar empatia. Leslie Bishko para abordar a forma como nos envolvemos empaticamente com ações de terceiros, refere um modelo da neurociência que explica a forma como nos identificamos com os valores expressos por outros: os neurónios espelho (Bishko 2014, 50). Os neurónios espelho atuam no cérebro como uma forma de replicar mentalmente o que foi observado numa determinada ação (Bishko 2014, 50). Portanto, podemos compreender através dos neurónios espelho a forma como nos revemos nas ações de outros, assim como nas ações dos elementos que figuram num determinado Gif animado. Partindo do conceito de empatia de Hooks e da explicação dos neurónios espelho por Bishko, pensamos que os Gifs animados auxiliam os utilizadores na cibercultura a contar melhor as suas histórias, as suas vivências. Hooks sugere que "nós somos animais contadores de histórias. É uma das nossas características mais marcantes. Nós alternamos a contar histórias de um para o outro, e podemos ter empatia com personagens fictícios. (...) Tudo significa alguma coisa, incluindo a nossa facilidade notável de contar histórias e fingir" (Hooks 2017). Assim como os memes batalham pela atenção dos seus anfitriões (Shifman 2014, 9), os Gifs batalham pela atenção dos utilizadores apelando à sua empatia.

\section{Processo de descontextualização}

Possivelmente a maior plataforma de Gifs, conhecida como "Google dos Gifs", é a Giphy. A Giphy é uma plataforma onde o utilizador tem acesso imediato, e de uma forma simples, a milhões de Gifs, através de rápidas pesquisas por palavras-chave. Permite também que o utilizador possa fazer upload e criar os seus próprios Gifs de uma forma intuitiva. Através do acesso a páginas individuais de Gifs, o utilizador pode descarregar ou embeber imediatamente em diversas redes sociais, por exemplo. Proveniente da Giphy, o Gif (Figura 1) presente neste texto, foi dividido 
em fotogramas individuais de forma a exemplificar a sequência de um comum Gif de reação. Este Gif apresenta-nos Howdie Mandel no programa America's Got Talent, a expressar um "uau", uma expressão de surpresa. Independente do contexto do "uau" original expresso por Mandel, os utilizadores podem recorrer a este mesmo Gif com conotações distintas. Consoante o contexto, este "uau", esta expressão de surpresa pode ser empregue com felicidade, com infelicidade ou até mesmo com desprezo. Esta é um exemplo sucinto da capacidade de descontextualização do Gif. Tendo em consideração as múltiplas utilizações de um mesmo Gif, em contextos diferentes, Gardies defende que "de facto, são as determinações contextuais que, ao nos tornarem sujeito leitor, regem a forma como produzimos sentido e afetações. As mesmas figuras mudam assim de significação conforme o contexto" (Gardies 2006, 191). Por norma, num Gif de reação figuram um conjunto de elementos que enquadram um único plano, e tendo em conta a definição de Gilles Deleuze, "o plano será considerado como o mais pequeno enunciado narrativo" (Deleuze 2015, 44). Desta forma podemos considerar um Gif como um exemplo de micronarrativa. Os Gifs de reação apresentam-se como uma possível máquina de criação de significado operada por todos os utilizadores que recorram às suas características comunicativas para expressar uma determinada emoção. Quanto mais utilizado, em contextos distintos, mais camadas de significado são adicionadas ao Gif. Isto traduz-se numa possível instabilidade da sua semiótica (Miltner and Highfield 2017,6 ), pois o seu significado vai mudando tanto quanto a vontade e interpretação dos utilizadores enquanto emissores e recetores. "Maior parte do significado original é perdido pois Gifs e memes encontram novas contextualizações ao longo de diferentes meios" (Tolins and Samermit 2016, 88). Da investigação e análise bibliográfica realizada, constatase que a discussão sobre a descontextualização do Gif acontece sobre a sua utilização em distintos contextos. Consideramos a utilização do Gif um dos possíveis níveis de descontextualização. Julgamos existir espaço para arriscar neste artigo outros níveis que passamos a enunciar: descontextualização ao nível da recriação, ao nível do remix, ao nível da identidade online.

Entendemos que o nível da recriação acontece quando existe a apropriação de produtos audiovisuais preexistentes para a produção de Gifs animados, sejam estes produtos audiovisuais provenientes da televisão, do cinema, ou registos pessoais. Nesta perspetiva, remetemos este conceito para a "remediação" explorado por Jay Bolter, onde os designers, os produtores apoderam-se das "práticas representacionais de outro média" (Bolter 2012, 3). Ou seja, o Gif enquanto média, opera esta remediação através dos seus produtores com a apropriação de conteúdos de outros média como a televisão e o cinema. E segundo Bolter, esta "remediação pode funcionar em qualquer direção: novos média podem servir-se de uns mais antigos, ou médias mais antigos de uns mais novos. Numa economia de complexos média como a nossa, todos os vários média estão ocupados a servirem-se e refazendo-se mutuamente" (Bolter 2012, 3). No caso de remediação por parte do Gif em conteúdo cinematográfico, por exemplo, existe uma transição de características da narrativa visual do cinema como o trabalho de câmara, de composição, de personagens, etc.

A partir do momento que um determinado Gif se torne viral e atinja um determinado nível de popularidade, segundo a ideia de Limor Shifman, é muito provável que ramificações daquele Gif surjam através de novas interpretações, através de remix de conteúdo (Shifman 2014, 58). Neste sentido, Shifman defende a ideia que "conteúdo puramente viral provavelmente não existe" (Shifman 2014, 58). A propósito do conceito de remix, Campanelli afirma que produtor e utilizador "finalmente se encontram no mesmo lado de uma galáxia mediática interconectada" (Camponelli 2012 , 8). Esta facto leva Campanelli a explorar um paralelismo entre o conceito de bricoleur e o conceito mais atual e comummente chamado de remixer, numa vertente de criar novos produtos recorrendo a matéria-prima preexistente e imediatamente disponível "(reconhecidamente, estas não são difíceis de encontrar em uma era de abundância)" (Camponelli 2012 , 9). Neste sentido, consideramos que o remix se tornou acessível às massas, uma vez que a tecnologia e o desenvolvimento de algoritmos desenvolveram-se rapidamente, de forma a proporcionar uma experiência cada vez mais simples e imediata ao utilizador. Desta forma o utilizador produz novos conteúdos através da sua mistura, colocando-os em circulação nas redes. A "tecnologia deu a muitas pessoas a oportunidade de criar, modificar ou hibridizar objetos dos média" (Camponelli 2012, 11). E enquanto seres humanos, presumimos que nos sentimos atraídos por este espírito do it yourself e pelo acesso imediato a poderosas ferramentas de criação e edição de imagem. Operar com estas ferramentas, independentemente de existir, ou não, um nível técnico de qualidade profissional, é aparentemente uma das formas mais atuais dos utilizadores sentirem-se cada vez mais envolvidos na cibercultura. As barreiras entre produtor profissional e consumidor estão aparentemente destruídas, emergindo consumidores também como produtores. Independentemente que o aspeto final do produto possa manifestar um caráter profissional ou amador, sugerimos a ideia que o mais importante é ser eficaz na comunicação. "Se tudo é tão prático, tão extemporâneo e tão divertido, por que não remixálo?"(Camponelli 2012, 14). Descontextualizações em cima de descontextualizações, seja por recriação, por utilização, ou por remix, os Gifs "são como zombies e pod people. Eles podem voltar, mas nunca são iguais. Algo mudou: resolução, proporção, tamanho. Ou o material da imagem ficou incrustado de memes" (McCarthy 2018, 114), neste "mundo caótico de conteúdo gerado pelos utilizadores" (Shifman 2014, 8).

Tolins e Samermite sugerem que na utilização de Gifs de reação, os utilizadores recorrem a "comportamentos de outros como representação da sua própria ação" (Tolins and Samermit 2016, 88). Identificamos aqui uma descontextualização que acontece ao nível da própria identidade. Atuando ao nível do utilizador e 
da sua identidade atrás do ecrã que, fazendo alusão ao conceito de máscara desenvolvido anteriormente neste artigo, se descontextualiza a si mesmo aquando do momento que recorre a ações de terceiros como se das suas próprias ações se tratassem. No seguimento desta ótica, a recorrente utilização de Gifs também contribui para a construção de uma online persona, e esta é uma construção gradual e flexível (Marwick 2013, 356; Schmidt 2013, 365). Segundo Moore, Barbour e Lee, no seu artigo onde sustentam cinco dimensões da online persona, no ponto "Dimensão Performativa da Persona", sugerem que "precisamos de levar a cabo a nossa identidade, a nossa profissão, o nosso género $e$ firmar os nossos gostos, interesses e redes de conexão, através de atividades como comentar posts, colocar like em contribuições de outros ou enquadrar uma selfie" (Moore, Barbour, and Lee 2017, 3), assim como recorrer a Gifs de reação como forma de comunicar. A identidade online "implica a existência de uma distinção entre como as pessoas se apresentam online e como elas o fazem offline" (Marwick 2013, 358) e "geralmente é expressa por meio de personalização" (Marwick 2013, 358). A personalização, dado o contexto deste artigo, na criação de uma identidade online julgamos ser um aspeto importante para a sua construção, pois derivado da abundância de Gifs disponíveis para utilização, pode-se construir uma coletânea específica dentro dos parâmetros estabelecidos por cada utilizador no momento de reagir visualmente. Se, por exemplo, construirmos uma base de Gifs com incidência em sequências de Charlie Chaplin, estaremos a demonstrar a emoção que entendermos assim como a possibilidade de conhecermos a obra de Chaplin. Portanto, os utilizadores devem escolher as máscaras com que pretendem se apresentar online (Marwick 2013, 361).

Os vários possíveis níveis de descontextualização do Gif de reação avançados neste texto, levam-nos a acreditar numa espiral infinita de significação e descontextualização. Procuramos sustentar esta ideia com base no que Deleuze interpreta de Peirce, na sua obra Cinema imagem-tempo: "o signo é uma imagem que vale para outra imagem (o seu objecto) sob a relação de uma terceira imagem que constituiu o seu «interpretante», sendo este por sua vez um signo e assim até ao infinito" (Deleuze 2015, 53). Esta terceira imagem, a interpretação, julgamos que se torna um dos principais responsáveis pelo apelo à criatividade perante a possibilidade de novos Gifs através de criação, recriação ou remix, acrescentando-lhes novos valores, novos significados, que por sua vez poderão ser novamente descontextualizados nesta espiral ascendente e sem fim.

\section{Considerações finais}

Ao longo do presente artigo procuramos construir uma resposta, um contributo que pudesse realçar a importância do Gif animado através da exploração do conceito de Gif de reação, e da sua associada descontextualização. Parte das conclusões que pudemos constatar, recaíram nas características do
Gif propícias à cibercultura, como a capacidade de apresentar imagem em movimento, ser facilmente e rapidamente consumido, existir abundância de matéria-prima tanto para produção como implementação, apresentar eficácia na indução de emoção assim como a habilidade de acompanhar e substituir palavras. Propícias à comunicação neste universo digital que tem vindo a atingir ritmos elevados (Martins 2012, 55; Neves and Pinto-Coelho 2010, 5), e "nós fomos, com efeito, alienados da nossa condição propriamente histórica" (Martins 2012, 55), assim como "em muito do que fazemos e do que é feito connosco, do que percepcionamos e do que pensamos, dificilmente conseguimos estar separados dos ecrãs" (Neves and Pinto-Coelho 2010, 5). Neste sentido, Gunther Kress e Theo van Leeuwen reforçam a importância da literacia visual nas comunidades como forma de preparar o futuro, pois acreditam que a "a comunicação visual tem vindo a ser cada vez menos do domínio de especialistas, e cada vez mais crucial nos domínios da comunicação pública" (Kress and Leeuwen 2006, 3).

Os utilizadores recorrem às características do Gif como forma de demonstrar afeto real ou hipotético em múltiplas situações, como já demonstradas anteriormente neste artigo. Quando por palavras, por vezes é complicado expressar determinado afeto, um Gif pode descomplicar, tornando este processo mais simplificado, intuitivo e apelativo, tanto ao emissor como ao recetor da mensagem.

Ao mesmo tempo, contudo, cada meio tem suas próprias possibilidades e limitações de significação. Nem tudo o que pode ser realizado na linguagem pode também ser realizado por meio de imagens, ou vice-versa (Kress \& Leeuwen, 2006, p. 19).

Consideramos que o Gif ocupa o seu espaço na comunicação assim como as palavras, a imagem estática, o vídeo, o som, etc. Pensamos que se apresenta como uma solução, uma solução com características próprias que pode desempenhar melhor a sua função em determinados contextos e pior noutros, como qualquer outro meio.

Estaremos perante a linguagem visual dos Gifs? Travis Rich e Kevin Hu, criadores da plataforma GIFGIF (Rich and Hu n.d.) e investigadores do MIT Media Lab, acreditam que sim.

\footnotetext{
"Nós estávamos a falar sobre Gifs um dia", disse Hu a Quartz, "e percebemos que eles estão a tornarse cada vez mais sérios enquanto média. Eles são mais populares, eles são usados para mais coisas" (Feltman and Quartz 2014).
}

Acreditamos que este formato de imagem evoluiu naturalmente e gradualmente pela recorrente utilização por parte dos seus utilizadores. Pensamos que o Gif assumiu um patamar sólido entre imagem estática e vídeo impondo todo o seu potencial comunicativo. O Gif foi um formato que se julgava morto durante a transição entre milénios, mas regressou à ribalta anos depois através de uma crescente utilização em plataformas como o Tumblr. GIFGIF é uma plataforma online, um 
website que pretende quantificar a emoção transmitida pelos Gifs, e proporcionar aos utilizadores uma forma de pesquisa por emoções, ao invés de uma pesquisa tradicional, por palavras-chave (Rich and Hu n.d.). Rich e Hu recolhem dados de um simples questionário com apenas três opções de resposta que a plataforma dispõe aos seus utilizadores. Desta forma, acabam por conseguir perceber a mudança de significado dos Gifs, em termos emocionais, dependendo do país, da cultura, que o utilizador pertence.

O seu primeiro objetivo é construir um tradutor de texto-para-Gif. "Quero que as pessoas consigam colocar um soneto de Shakespeare e obtenham um conjunto de GIFs", disse Hu. Mas uma vez que eles consigam métricas qualitativas para um grande número de GIFs, eles acham que as possibilidades são infinitas (Feltman and Quartz 2014).

Apesar de pressupormos que este tradutor textopara-Gif pode ser um objetivo ambicioso, acreditamos que possa ser possível um dia. Contudo, textopara-Gif remete-nos para a criação de narrativas. É possível encontrar curtos Gifs na internet que foram construídos de forma a constituírem uma sequência de eventos, uma narrativa segundo uma definição clássica de David Bordwell, Kristin Thompson e Jeff Smith (Bordwell, Thompson, and Smith 2017, 73). Uma narrativa feita de diversos enquadramentos que podem ter origens completamente distintas. Mais uma vez recorremos ao conceito de "remediação" de Bolter, pois os utilizadores/produtores destes Gifs socorrem-se de conceitos associados ao cinema para contarem as suas histórias. De acordo com Bolter, "uma das razões para esse empréstimo de convenções cinematográficas é que décadas de filmagem tornaram essas convenções naturais para nossa cultura: aceitamos isso como a maneira de ver o desdobramento de uma narrativa visual" (Bolter 2012, 3). Técnicas que se tornaram transparentes, consensualmente aceites pela sociedade (Bolter 2012 , 3), que são transportadas e adaptadas às características do Gif como forma de contar uma curta história, muitas vezes com uma tendência humorística. Estas narrativas abrem espaço para uma investigação mais profunda nesse sentido. Perceber até que ponto um curto Gif, constituído por eventos sequenciais, pode comunicar eficazmente uma história. Suportamos a importância desta linha investigação do Gif com base nas palavras de Sousa, Zagalo e Martins onde defendem que "autores como Mark Turner ou Jerome Bruner (cit. por Ryan, 2004: 3) enfatizam a capacidade narrativa como instrumento fundamental da cognição humana" (Sousa, Zagalo, and Martins 2012, 167), e Bordwell, Thompson e Smith referem que "a narrativa é uma maneira fundamental de os humanos entenderem o mundo" (Bordwell, Thompson, and Smith 2017, 72).

Miltner e Highfield afirmam que a "ingenuidade sem fim dos seres humanos em ambientes digitais significa que a história dos Gifs-e a exploração de todo o seu potencial—provavelmente está apenas a começar" (Miltner and Highfield 2017, 9), assim como "o Gif provavelmente continuará a ser um padrão do setor, apesar da superioridade técnica de alternativas como Png e Jpeg, porque é o único formato gráfico comum que suporta animação" (Geer 2003, 89). Estes são ingredientes que, a nosso ver, formulam uma receita importante para que os utilizadores possam contar as suas histórias e, ao mesmo tempo, contribuírem para que o Gif também possa continuar a pautar a sua própria história.

\section{Bibliografia}

Bakhshi, Saeideh, David Shamma, Lyndon Kennedy, Yale Song, Paloma Juan, e Joseph Kaye. 2016. 'Fast, Cheap, and Good: Why Animated GIFs Engage Us'. Proceedings of the $2016 \mathrm{CHI}$ Conference on Human Factors in Computing Systems, 575-86.

Bishko, Leslie. 2014. 'Our Empathic Experience of Believable Characters'. In Nonverbal Communication in Virtual Worlds: Understanding and Designing Expressive Characters, editado por Joshua Tanenbaum, Magy Seif ElNasr, e Michael Nixon, 47-59. ETC Press.

Bolter, Jay David. 2012. 'Digital Media and the Future of Filmic Narrative'. In The Oxford Handbook of Film and Media Studies, editado por Robert Kolker, 1-20. Oxford: Oxford Handbooks Online.

Bordwell, David, Kristin Thompson, e Jeff Smith. 2017. Film Art: An Introduction. 11th ed. New York: McGraw-Hili.

Burgoon, Judee K., Laura K. Guerrero, e Kory Floyd. 2016. Nonverbal Communication. New York: Routledge.

Camponelli, Vito. 2012. 'Remix It Yourself. A Do It Yourself Ethic'. Comunicação e Sociedade 22: 8-15.

Chen, Weixuan, Ognjen Rudovic, e Rosalind Picard. 2017. 'GIFGIF+: Collecting Emotional Animated GIFs with Clustered Multi-Task Learning'. 2017 Seventh International Conference on Affective Computing and Intelligent Interaction (ACII), 510-17.

Deleuze, Gilles. 2015. A Imagem-Tempo. 10 Edição. Lisboa: Documenta.

Eppink, Jason. 2014. 'A Brief History of the GIF (so Far)'. Journal of Visual Culture 13 (3): 298-306.

Feifer, Jason. 2016. 'IT'S A GIF, GIF, GIF, GIF WORLD'. Entrepreneur, 2016.

Feltman, Rachel, e Quartz. 2014. 'These MIT Researchers Want to Turn GIFs Into a Language'. 2014. https://www.theatlantic.com/education/archive/2014/03/ these-mit-researchers-want-to-turn-gifs-into-alanguage/284322/.

Freitas, Ricardo, e Francine Pereira. 2017. 'Embates No Ciberespaço: Leitores Reais e Os Prosumers de Gifs E Webcomics'. Linguagem: Estudos e Pesquisas 21 (2): 195-207.

Fresko, David. 2013. 'Muybridge's Magic Lantern'. Animation: An Interdesciplinary Journal 8 (1): 47-64.

Gardies, René. 2006. Compreender o Cinema e as Imagens. Lisboa: Edições Texto \& Grafia.

Geer, Sean. 2003. Essential Internet. London: Profile Books Ltd.

Hesselberth, Pepita, e Maria Poulaki. 2018. 'Introduction: Screen | Capture | Attention'. In Compact Cinematics: The Moving Image in the Age of Bit-Sized Media, editado por Pepita Hesselberth e Maria Poulaki. New York: Bloomsbury Publishing Inc.

Hillis, Ken, Susanna Paasonen, e Michael Petit, eds. 2015. Networked Affect. The MIT Press.

Hooks, Ed. 2017. Acting for Animators. 4th ed. New York: Routledge. 
Innis, Harold. 2008. The Bias of Communication. Toronto: University of Toronto Press Incorporated.

Jenkins, Henry, Sam Ford, e Joshua Green. 2013. Spreadable Media: Creating Value and Meaning in a Networked Culture. New York: New York University Press.

Kress, Gunther, and Theo van Leeuwen. 2006. Reading Images: The Grammar of Visual Design. 2nd ed. Oxfordshire: Routledge.

Maffesoli, Michel, e Moisés de Lemos Martins. 2011. 'Ciberculturas'. Revista de Comunicação e Linguagens, 41-52.

Manovich, Lev. 2002. The Language of New Media. 1st ed. Massachusetts: The MIT Press.

Martin, Katherine Connor. 2012. 'Oxford Dictionaries USA Word of the Year 2012 Is "to GIF"'. Oxford Dictionaries. 2012. https://blog.oxforddictionaries.com/2012/11/12/usword-of-the-year-2012/.

Martins, Moisés. 2012. 'Media Digitais - Hibridez, Interatividade, Multimodalidade'. Revista de Comunicação e Linguagens, 49-60.

Martins, Moisés. 2016. 'Faces Olhando a Pop Art e o Desenho Gráfico'. In Pintomeira, 321-33. Viana do Castelo: Câmara Municipal de Viana do Castelo.

Marwick, Alice E. 2013. 'Online Identity'. In A Companion to New Media Dynamics, editado por John Hartley, Jean Burgess, e Axel Bruns, 355-64. Chichester: Blackwell Publishing Ltd.

McCarthy, Anna. 2018. 'Visual Pleasure and GIFs'. In Compact Cinematics: The Moving Image in the Age of Bit-Sized Media, editado por Pepita Hesselberth e Maria Poulaki. New York: Bloomsbury Publishing Inc.

Miltner, Kate, e Tim Highfield. 2017. 'Never Gonna GIF You Up: Analyzing the Cultural Significance of the Animated GIF'. Social Media + Society 3: 87-96.

Moore, Christopher, Kim Barbour, e Katja Lee. 2017. 'Five Dimensions of Online Persona'. Persona Studies 3 (1): 1-11.

Neves, José Pinheiro, e Zara Pinto-Coelho. 2010. '“Em Direcção Ao Vazio Ou a Qualquer Coisa": Os Ecrãs e as Ligações Quotidianas Sociotécnicas'. Comunicação e Sociedade 17: 5-7.

Newman, Michael Z. 2016. 'GIFs: The Attainable Text'. Film Criticism 40 (1).

Nordau, Max. 1898. Degeneration. Popular Ed. London: William Heinemann.

Rich, Travis, e Kevin Hu. n.d. 'GIFGIF'. Acedido em 27 de dezembro de 2018. http://gifgif.media.mit.edu/about.

Schmidt, Jan-Hinrik. 2013. 'Practices of Networked Identity'. In A Companion to New Media Dynamics, editado por John Hartley, Jean Burgess, e Axel Bruns, 365-73. Chichester: Blackwell Publishing Ltd.

Shifman, Limor. 2014. Memes in Digital Culture. The MIT Press.

Sousa, Marta, Nelson Zagalo, e Moisés Martins. 2012. “Eu Também Posso Propagar Histórias". A Adaptação e as Narrativas Transmediáticas Na Era Da Participação'. Comunicação e Sociedade 22: 167-83.

Thompson, Clive. 2013. 'The Animated Gif: Still Looping after All These Years'. Wired. 2013. https://www.wired. com/2013/01/best-animated-gifs/.

Tolins, Jackson, e Patrawat Samermit. 2016. 'GIFs as Embodied Enactments in Text-Mediated Conversation'.

Väliaho, Pasi. 2018. 'Solitary Screens: On the Recurrence and Consumption of Images'. In Compact Cinematics: The Moving Image in the Age of Bit-Sized Media, editado por Pepita Hesselberth e Maria Poulaki. New York: Bloomsbury Publishing Inc. 